Supporting Information

\title{
Oxygen-Less Carbon Nanodots with Absolute Quantum Yield of 80\% for Display Applications
}

Taehyung Lee ${ }^{1,2, \S}$, Sungyeon Won ${ }^{3, \S}$, Yoonsang Park ${ }^{1,2, \star}$, and Woosung Kwon ${ }^{1,3, \star}$

${ }^{1}$ Institute of Advanced Materials and Systems, Sookmyung Women's University, Seoul 04310,

South Korea

${ }^{2}$ Department of Chemical Engineering, Pohang University of Science and Technology (POSTECH), Pohang 37673, South Korea

${ }^{3}$ Department of Chemical and Biological Engineering, Sookmyung Women's University, Seoul 04310, South Korea

$\S$ These authors equally contributed to this work.

${ }^{\star}$ Corresponding author.

Tel.: +82 220777398; Fax: +82 220777278; E-mail: wkwon@sookmyung.ac.kr

Tel.: +82-2-6325-3191; Fax: +82-2-6325-3192; E-mail: p1234011@postech.ac.kr 


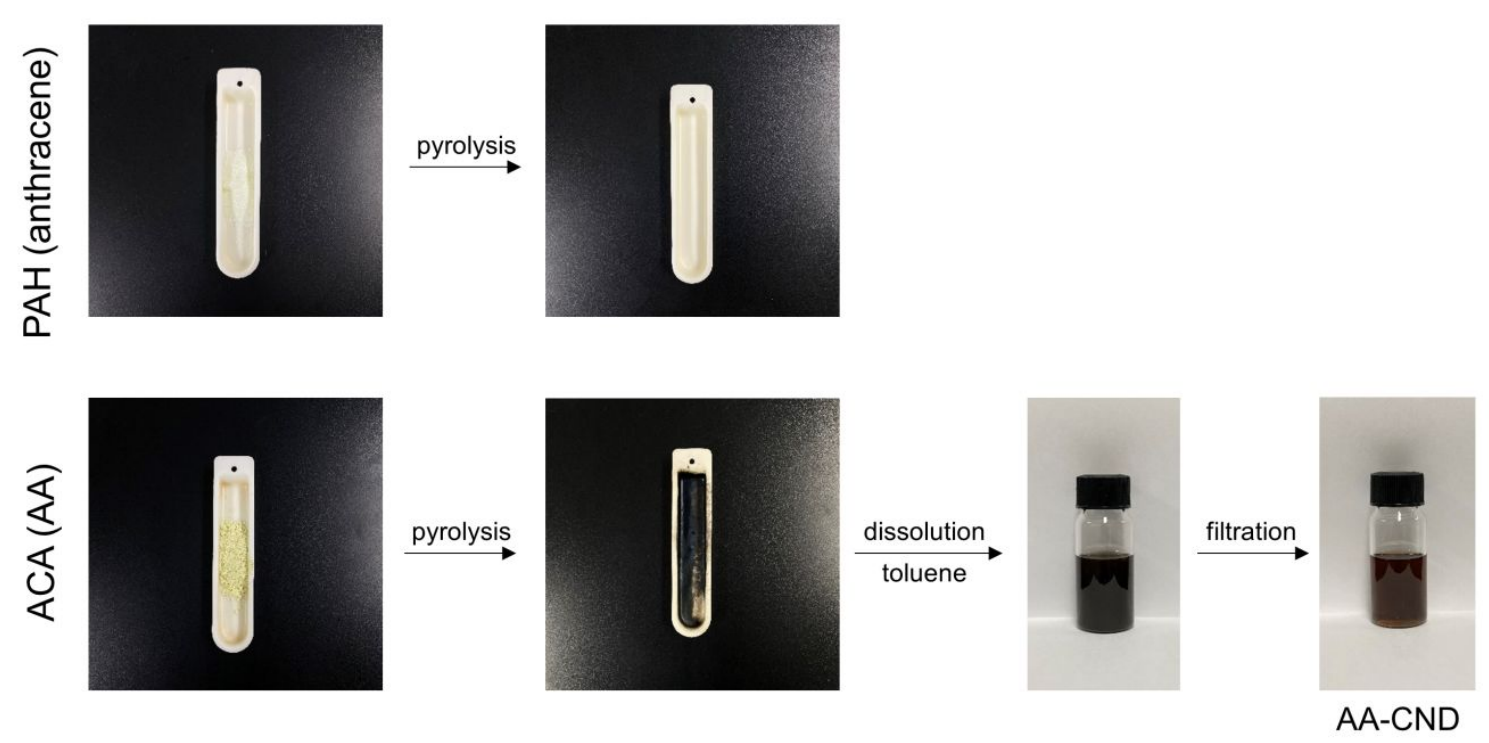

Figure S1. photo of pyrolysis of PAH (anthracene) and ACA (AA). Carbonized product was collected by toluene and filtrated to yield CND.

Table S1. Synthesis conditions and the results of various temperature of precursors

\begin{tabular}{c|c|c|c|c}
\hline Precursors & $200{ }^{\circ} \mathrm{C}$ & $300{ }^{\circ} \mathrm{C}$ & $400{ }^{\circ} \mathrm{C}$ & $500{ }^{\circ} \mathrm{C}$ \\
\hline \multirow{2}{*}{ AA } & & \multicolumn{3}{|c}{$\mathrm{O}$} \\
\cline { 3 - 4 } Anthracene & \multirow{2}{*}{$\mathrm{X}$} & $\mathrm{X}$ & Vaporization \\
\cline { 1 - 2 } & & \multicolumn{3}{|c}{$\mathrm{O}$} \\
\cline { 1 - 3 } PA & & $\mathrm{X}$ & Vaporization \\
\cline { 3 - 4 } & &
\end{tabular}

$X$ : No change

O: Carbonization occurring 
a

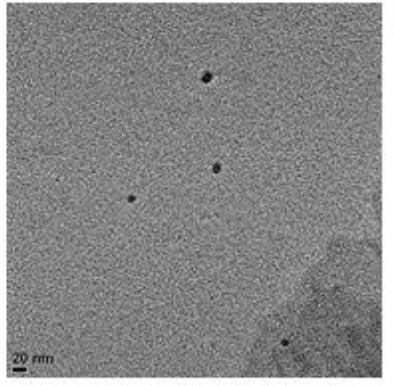

d

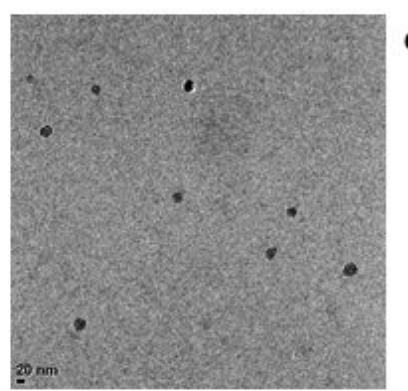

b

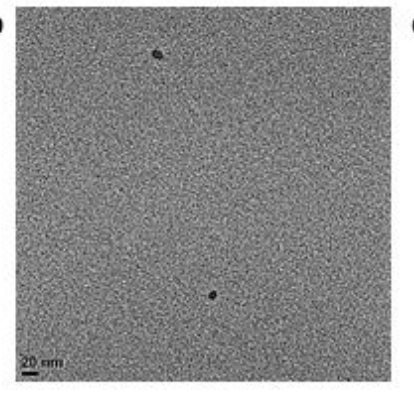

c
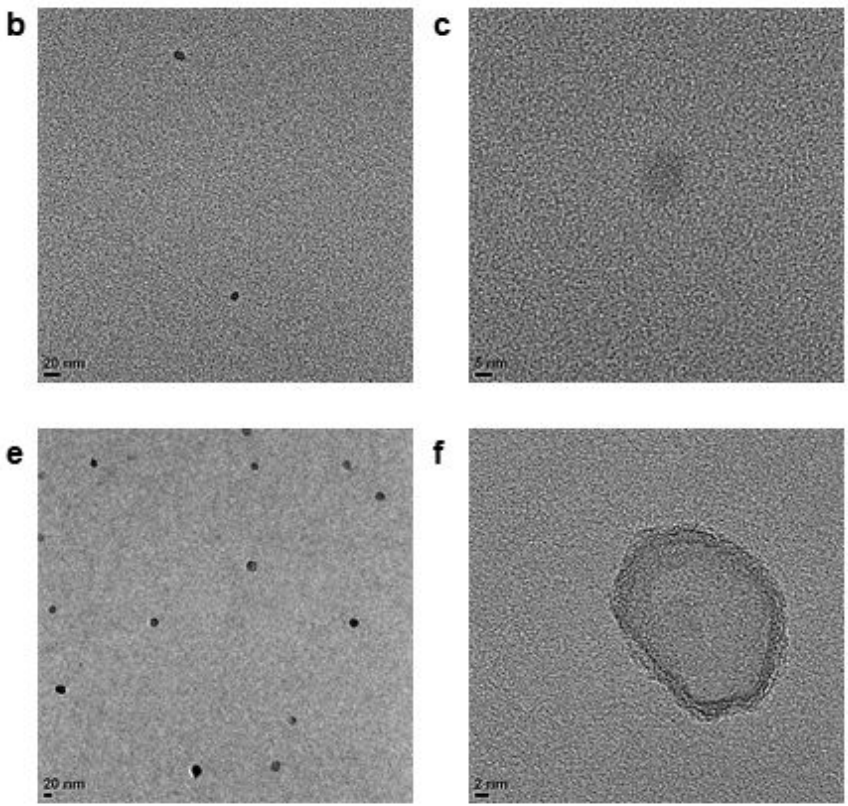

Figure S2. Additional TEM images of (a-c) AA-CNDs and (d-f) PA-CNDs. 

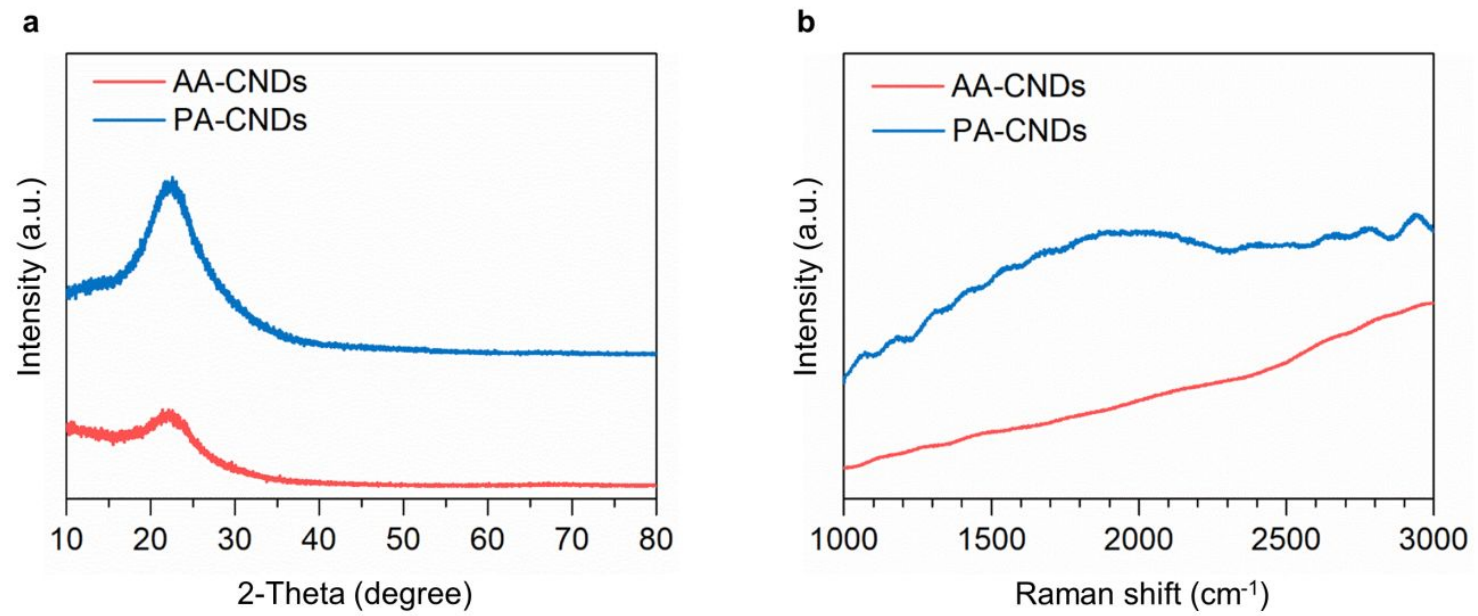

Figure S3. (a) XRD patterns of AA- and PA-CNDs. (b) Raman spectra of AA- and PA-CNDs using excitation wavelength of $532 \mathrm{~nm}$. 
a

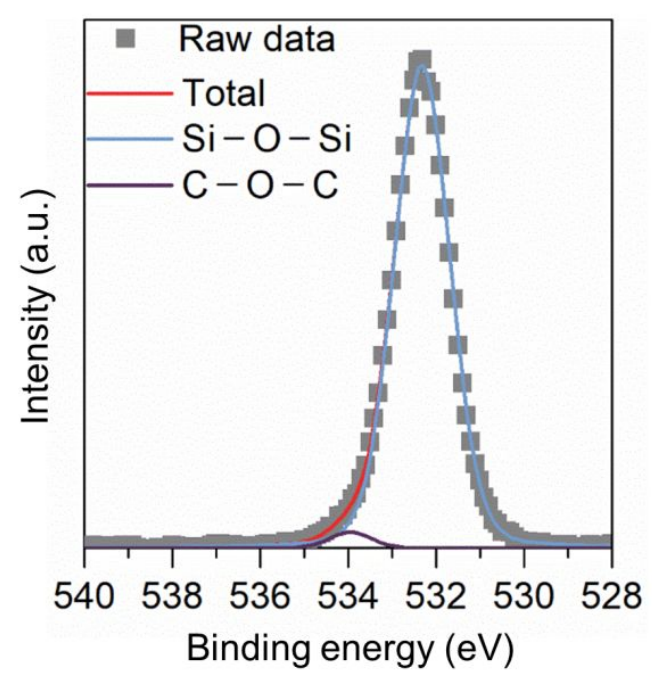

C

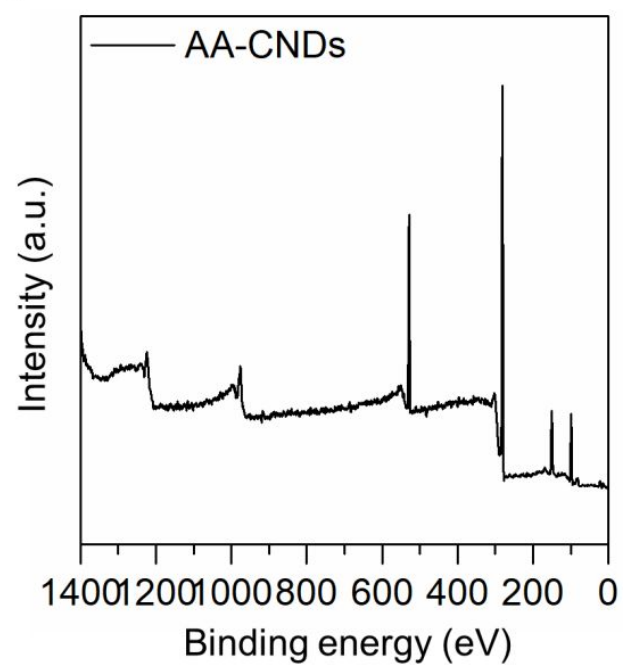

b

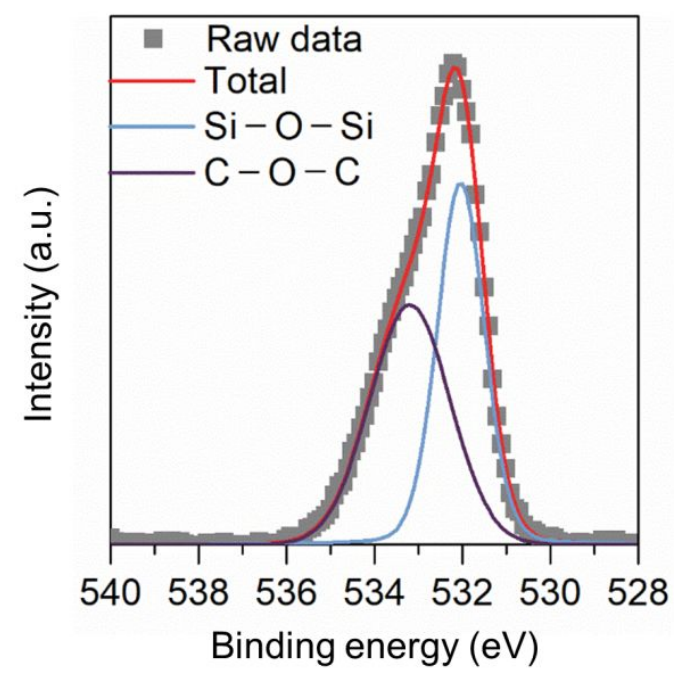

d

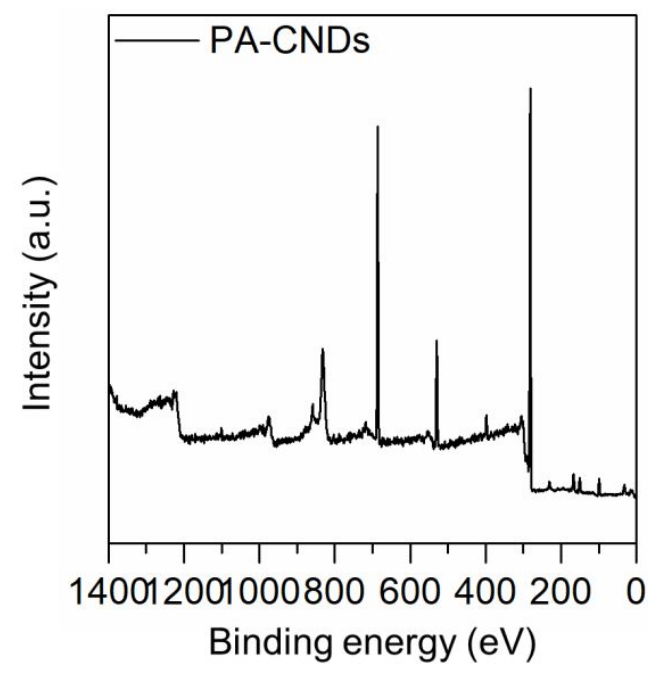

Figure S4. O1s XPS spectra of (a) AA-CNDs and (b) PA-CNDs. Overall XPS survey spectra of (c) AA-CNDs and (d) PA-CNDs. 
Table S2. Elemental analysis of atomic ratio in AA-CNDs and PA-CNDs.

\begin{tabular}{ccccccc}
\hline & \multicolumn{4}{c}{ Atomic ratio (\%) } \\
\cline { 2 - 5 } Sample & $\mathrm{C}$ & \multicolumn{2}{c}{$\mathrm{O}$} & \multirow{2}{*}{$\begin{array}{c}\text { O/C ratio } \\
(\%)^{*}\end{array}$} \\
\cline { 2 - 5 } & & $\mathrm{C}-\mathrm{O}-\mathrm{C}$ & $\mathrm{Si}-\mathrm{O}-\mathrm{Si}$ & & \\
\hline AA-CND & 71.31 & 0.43 & 18.43 & 9.84 & $\mathbf{0 . 6 0}$ \\
PA-CND & 82.88 & 7.33 & 6.84 & 2.96 & $\mathbf{8 . 8 4}$ \\
\hline
\end{tabular}

NOTE: Since the XPS samples were prepared by drop casting the solution of CND on silicon wafer, oxygen peak from the wafer ( $\mathrm{Si}-\mathrm{O}-\mathrm{Si}$ ) was overlapped in O1s XPS spectra (Figure S3). To reduce the oxygen content came from the wafer, atomic ratio of $\mathrm{C}-\mathrm{O}-\mathrm{C}$ was calculated from the deconvoluted spectra. The ratio of $\mathrm{Si}-\mathrm{O}-\mathrm{Si}$ to $\mathrm{Si}$ is nearly 2 , further confirming that these oxygen atoms belong to silicon atoms. 
a

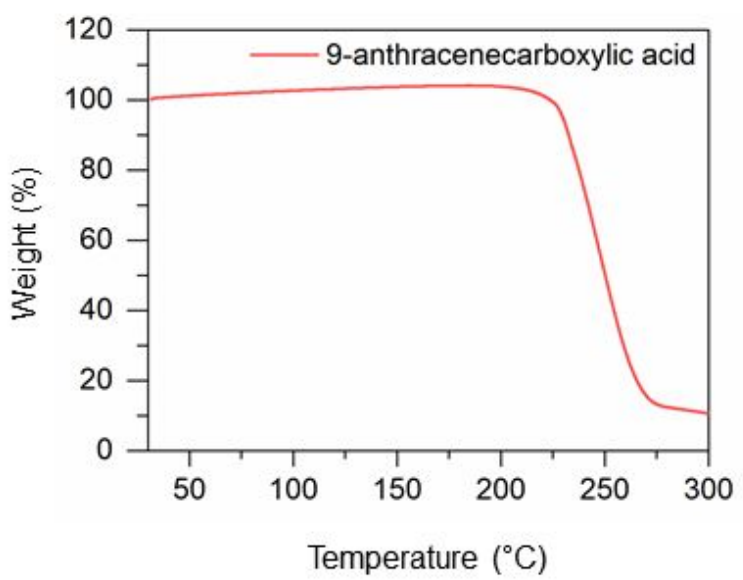

b

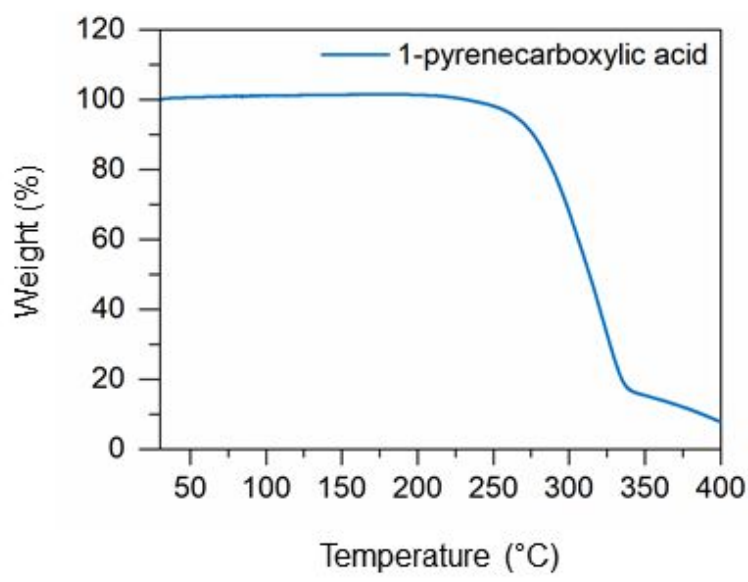

Figure S5. Thermogravimetric analysis (TGA) curves of (a) AA and (b) PA at heating rate of $5{ }^{\circ} \mathrm{C} / \mathrm{min}$ under $\mathrm{N}_{2}$ purging (gas flow $: 20 \mathrm{ml} / \mathrm{min}$ ). 


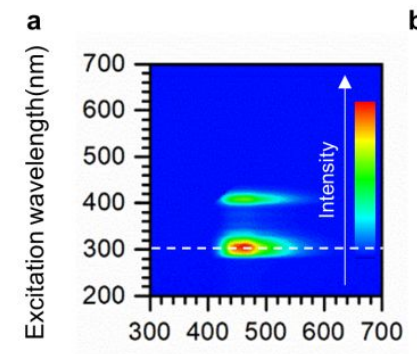

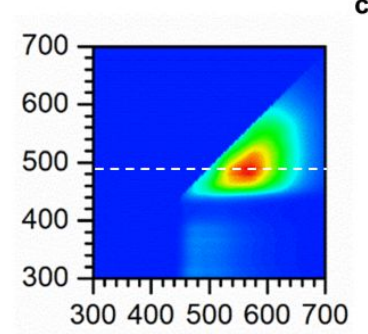

Emission wavelength $(\mathrm{nm})$
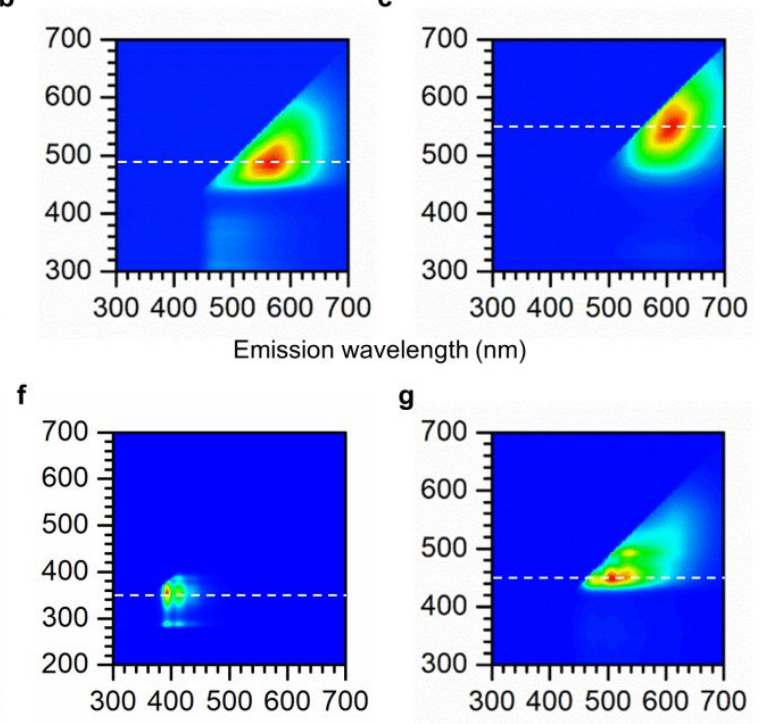

g

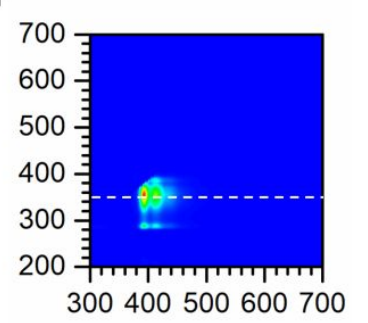

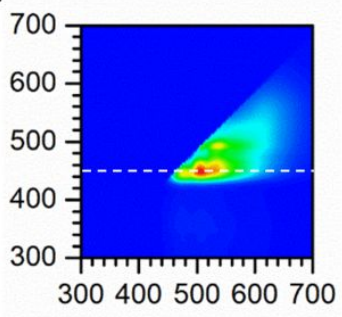

300400500600700 d

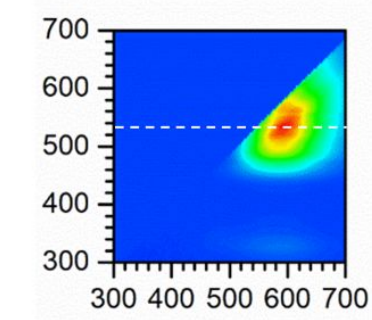

h

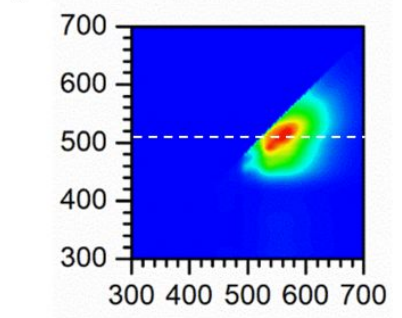

Emission wavelength (nm)

Figure S6. PL emission contour maps of (a) AA and (b-d) pyrolyzed product of AA at different reaction temperatures of 200,300 , and $400^{\circ} \mathrm{C}$, respectively. PL emission contour maps of (e) PA and (f-h) pyrolyzed product of PA at different reaction temperatures of 200,300 and $400^{\circ} \mathrm{C}$, respectively. 


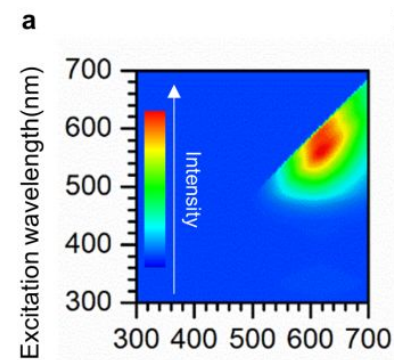

b

e

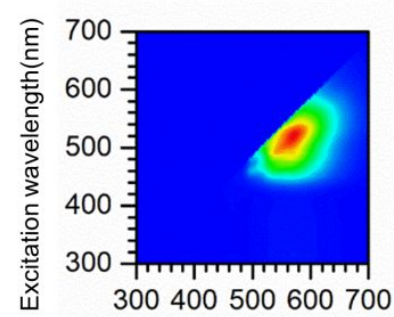

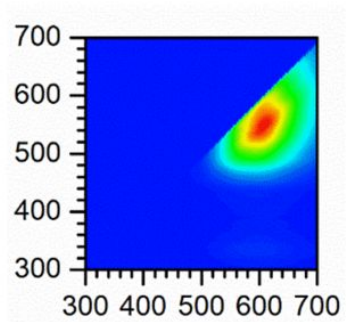

Emission wavelength ( $\mathrm{nm})$

C

g

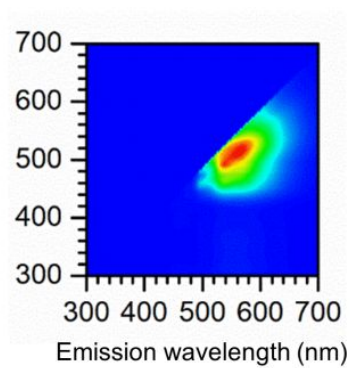

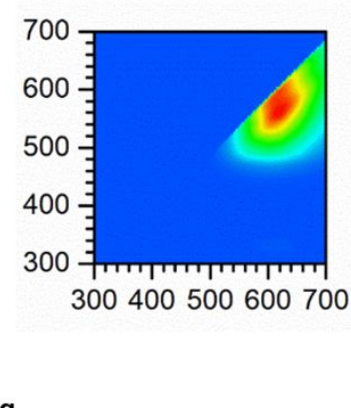

d

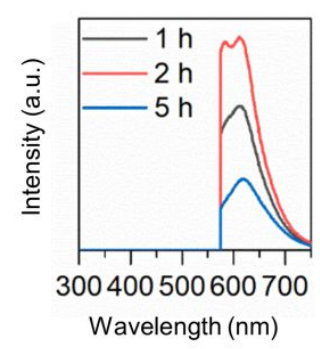

h

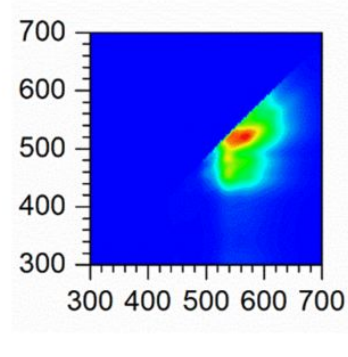

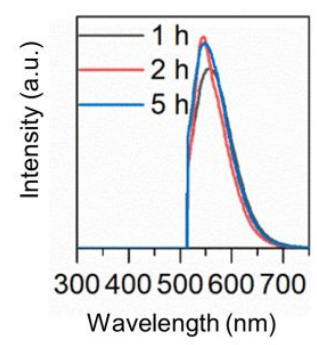

Figure S7. (a-c) PL emission contour maps at different reaction time conditions (1, 2, and 5h, respectively) of AA-CNDs. (d) Cross-sectional spectra of (a-c) at excitation wavelength of 550 nm. (e-g) PL emission contour maps at different reaction time conditions $(1,2$, and $5 \mathrm{~h}$, respectively) of PA-CNDs. (d) Cross-sectional spectra of (e-g) at excitation wavelength of 500 $\mathrm{nm}$. 
a

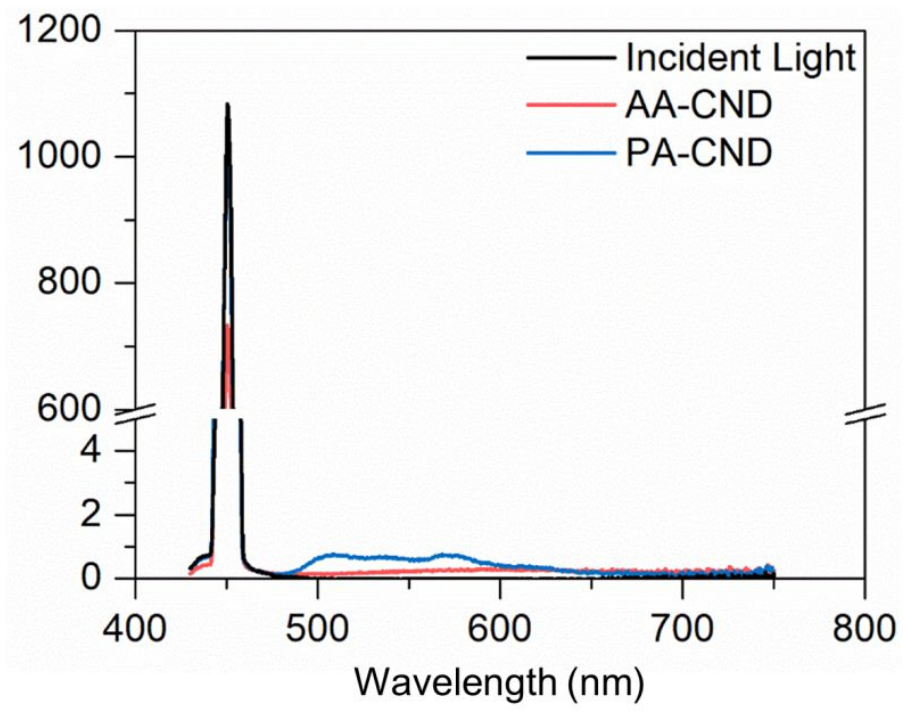

b

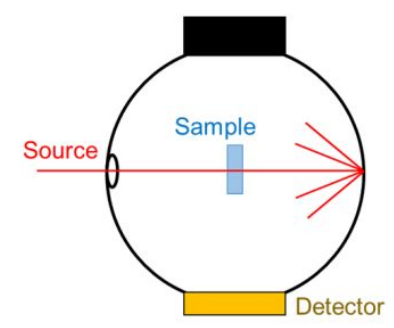

C

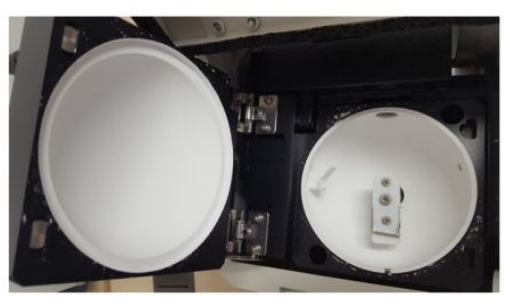

Figure S8. (a) Absolute quantum yield spectra of AA- and PA-CNDs. (b) Illustration of absolute quantum yield measuring system and (c) a photo of the integrating sphere setup.

\section{NOTE :}

The absolute quantum yields for the samples were calculated by the following equations:

$$
\text { Absolute Quantum Yield (\%) }=\frac{S_{0}-S_{1}}{S_{0}} \times 100
$$

$S_{0}=$ incident photon peak (area under the curve of Incident Light from 430 to $470 \mathrm{~nm}$ )

$S_{1}=$ the number of photons unabsorbed (area under the curve of AA- or PA-CND from 430 to $470 \mathrm{~nm}$ )

$S_{2}=$ the number of photons emitted (area under the curve of AA- or PA-CND from 470 to 750 $\mathrm{nm})$

Table S3. Calculated Quantum yields of AA- and PA-CNDs.

\begin{tabular}{c|c|c|c|c|c|c}
\hline Sample & $\begin{array}{c}\text { Ex. wavelength } \\
(\mathrm{nm})\end{array}$ & Absorptance (\%) & $\begin{array}{c}\text { Quantum } \\
\text { Yield (\%) }\end{array}$ & $\begin{array}{c}\text { Incident } \\
\text { Light }\end{array}$ & Fluorescence & Scattering \\
\hline AA-CND & 450 & 31.67726 & $\mathbf{2 . 9 1 0 0 9 8}$ & 6665.872 & 61.44864 & 4554.306 \\
PA-CND & 450 & 1.911772 & $\mathbf{8 0 . 4 2 2 5 9}$ & 6665.872 & 102.4875 & 6538.436 \\
\hline
\end{tabular}




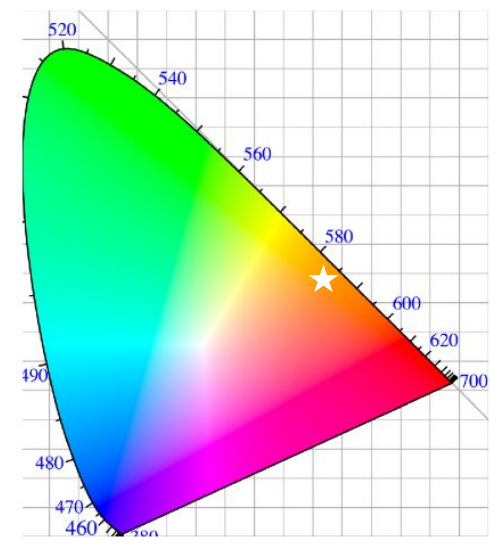

Figure S9. CIE chromaticity coordinates calculated from the PL spectrum. 
a

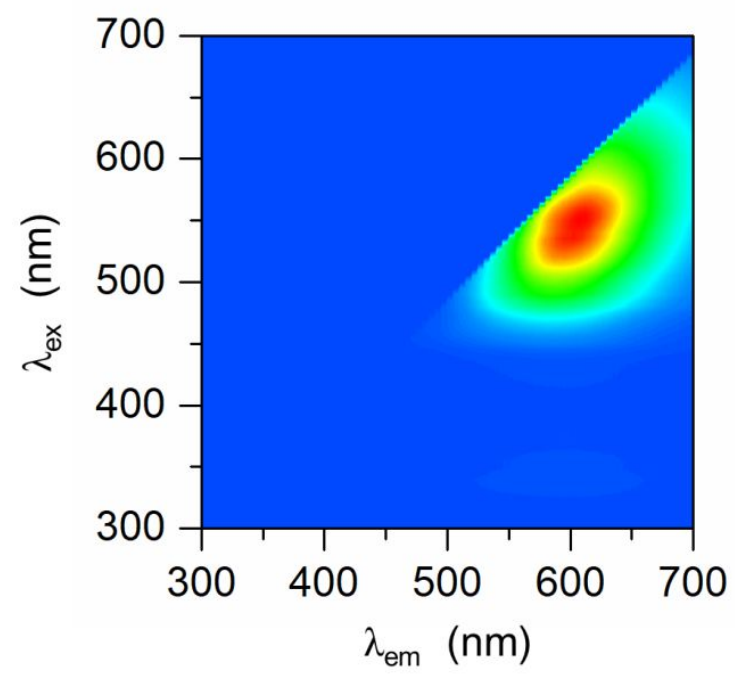

b

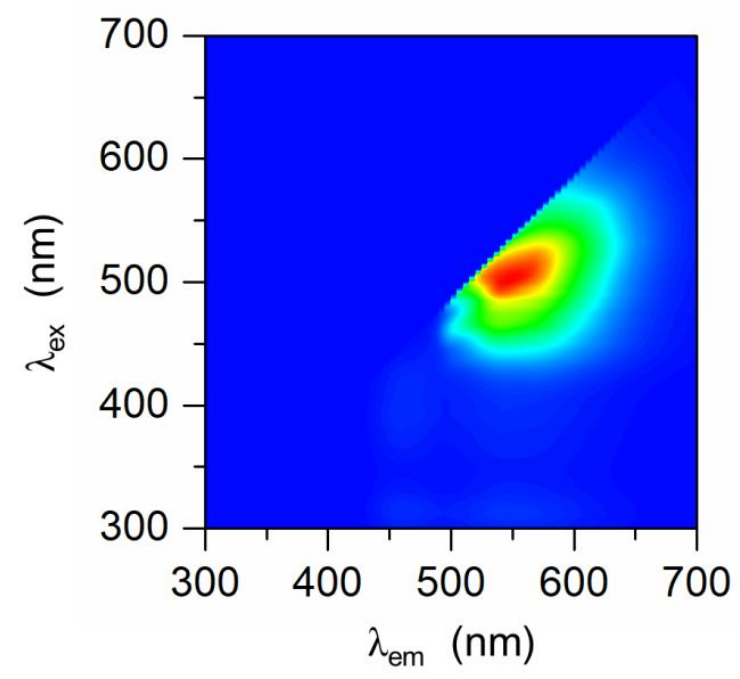

Figure S10. PL emission contour maps of (a) AA- in acetone and (b) PA-CNDs in acetone.

There are no PL spectra shift comparing to CNDs in toluene. 